\title{
LARYNGOLOGY
}

\section{Modular approach in OPHL: are there preoperative predictors?}

\author{
OPHL modulare: esistono parametri predittivi preoperatori?
}

\author{
Andy Bertolin1, Marco Lionello', Marco Ghizzo', Emanuela Barbero², Erika Crosetti³, Giuseppe Rizzotto', Giovanni Succo 3,4 \\ ${ }^{1}$ Otolaryngology Unit, Vittorio Veneto Hospital, Italy; ${ }^{2}$ Otorhinolaryngology Service, University of Eastern Piedmont, Novara, Italy; \\ ${ }^{3}$ Head and Neck Oncology Unit, Candiolo Cancer Institute, FPO-IRCCS, Candiolo (TO), Italy; ${ }^{4}$ Department of Oncology, University \\ of Turin, Orbassano (TO), Italy
}

\section{SUMMARY}

Objective. Open partial horizontal laryngectomies (OPHLs) nowadays represent the first line surgical choice for the conservative treatment of locally intermediate and selected advanced stage laryngeal cancers. Among the peculiarities of OPHLs, there is the possibility of intraoperatively modulating the procedure. It would be useful for the surgeon to recognise preoperative endoscopic and radiological factors that can predict the possibility to modulate the laryngectomy. Methods. The present study retrospectively reviewed a cohort of 72 patients who underwent OPHL for glottic LSCC, in order to identify preoperative (endoscopic and radiological) parameters that are able to predict modulation surgery.

Results. The hypoglottic extension of the glottic tumour was the preoperative finding that was most informative in predicting OPHL modulation. However, it had no significant impact on oncological outcomes.

Conclusions. Patients affected by tumours with hypoglottic extension and eligible for OPHL type II should be preoperatively informed about the possibility of an intraoperative switch towards OPHL type III.

KEY WORDS: OPHL, partial laryngectomy, modular, laryngeal carcinoma, hypoglottic extension

\section{RIASSUNTO}

Obiettivi. La laringectomia parziale orizzontale open (OPHL) rappresenta al giorno d'oggi la scelta chirurgica di prima linea per il trattamento conservativo del carcinoma squamoso laringeo (LSCC) in stadio intermedio e di selezionati casi in stadio localmente avanzato. Fra le peculiarità della OPHL c'è la possibilità di modulare intraoperatoriamente la procedura. Sarebbe utile al chirurgo riconoscere parametri preoperatori endoscopici elo radiologici che possano predire la possibilità di modulare intraoperatoriamente la laringectomia.

Metodi. Il presente studio ha considerato retrospettivamente una popolazione di 72 pazienti sottoposti ad OPHL per LSCC, al fine di identificare parametri preoperatori (endoscopici e radiologici) in grado di predire la modulabilità della $O P H L$.

Risultati. L'estensione ipoglottica del tumore è risultata essere il parametro preoperatorio più informativo nel predire la modulazione della OPHL. Tale condizione, tuttavia, non impattava in maniera significativo sull'outcome oncologico.

Conclusioni. I pazienti affetti da tumori con estensione ipoglottica e candidabili ad OPHL tipo II dovrebbero essere informati preoperatoriamente sulla possibilità di uno switch intraoperatorio verso una OPHL tipo III.

PAROLE CHIAVE: OPHL, laringectomia parziale, modulare, carcinoma laringeo, estensione ipoglottica

\section{Introduction}

Open partial laryngectomies have undergone worldwide diffusion from the second half of the $20^{\text {th }}$ century thanks to the efforts of some excellent surgeons. Alonso described supraglottic laryngectomy, indicated for tumours limited to
Received: April 3, 2020

Accepted: May 19, 2020

Correspondence

Marco Lionello

Otolaryngology Unit, Vittorio Veneto Hospital, via Forlanini 71, Vittorio Veneto, Treviso, Italy

E-mail: marcolionello@email.it

Funding

None.

Conflict of interest

The Authors declare no conflict of interest.

How to cite this article: Bertolin A, Lionello M, Ghizzo M, et al. Modular approach in OPHL: are there preoperative predictors? Acta Otorhinolaryngol Ital 2020;40:352-359. https://doi. org/10.14639/0392-100X-N0782

(C) Società Italiana di Otorinolaringoiatria e Chirurgia Cervico-Facciale

\section{(c) (1) (\$) $\odot$}

This is an open access article distributed in accordance with the CC-BY-NC-ND (Creative Commons Attribution-NonCommercial-NoDerivatives 4.0 International) license. The article can be used by giving appropriate credit and mentioning the license, but only for non-commercial purposes and only in the original version. For further information: https:// creativecommons.org/licenses/by-nc-nd/4.0/deed.en 
the supraglottic region ${ }^{1}$. A few years later Meyer, Piquet and Labayle standardised supracricoid laryngectomies with and without conservation of the suprahyoid epiglottis, respectively ${ }^{2,3}$. These became the most performed open partial laryngectomies worldwide, given their satisfying and reproducible results. In the 1970s, Serafini described a near-total laryngectomy, defined by a supratracheal caudal resection ${ }^{4}$, that was subsequently revised by Rizzotto who codified the tracheohyoidopexy as a supracricoid laryngectomy that extended toward the cricoid ${ }^{5}$. The requisite for the functional success of this technique was the possibility of sparing at least one crico-arytenoid unit (CAU).

Open partial laryngectomies nowadays represent the first line surgical choice for conservative treatment of locally intermediate and selected advanced stage laryngeal cancers.

According to the most recent guidelines of the European Laryngological Society (ELS), OPHL represents the current classification of horizontal partial laryngectomies ${ }^{6}$.

Both classifications are characterised by distinction of surgical subcategories according to the level of the caudal horizontal resection. We can therefore distinguish supraglottic laryngectomies (OPHL type I), supracricoid laryngectomies (OPHL Type II) and supratracheal laryngectomies (OPHL type III).

Among the peculiarities of OPHLs, there is the possibility to intraoperatively modulate the procedure.

It would be useful for the surgeon to identify preoperative endoscopic and radiological factors that can predict the possibility to modulate the laryngectomy. These factors should be considered and mentioned during preoperative counseling in order to allow the patient to participate in the therapeutic choice.

The main aim of the present study was to investigate, in a cohort of glottic LSCC patients undergoing OPHL, the preoperative factors that are related to modulation of the procedure. Secondary aims were to analyse the oncological outcomes of the cohort and the prognostic relevance of clinical, surgical and pathological parameters.

\section{Methods}

\section{Patients}

From 2015 to 2017, 119 patients underwent OPHL for glottic LSCC at the Otolaryngology Service of Vittorio Veneto Hospital, and the Otolaryngology Service of San Luigi Gonzaga University Hospital in Turin (Italy). Clinical charts were retrospectively reviewed.

Exclusion criteria were: i) patients with supraglottic cancer treated with supraglottic laryngectomy (OPHL I), since the primary aim of our study was to examine the factors influencing modularity in glottic cancer; ii) patients who un- derwent salvage OPHL; iii) patients with a follow-up $<24$ months; iv) a final histology other than LSCC.

Laryngeal tumours were staged according to the $8^{\text {th }}$ classification of the Union Internationale Contre le Cancer and the American Joint Committee on Cancer ${ }^{7}$.

Preoperative diagnostic work-up included laryngeal indirect flexible video-endoscopy, contrast-enhanced neck CT scan or MRI, chest X-ray; under general anaesthesia laryngoscopy was then performed using rigid $0^{\circ}, 30^{\circ}$ and $70^{\circ}$ telescopes in white light and narrow band imaging to complete the diagnostic work-up.

All patients preoperatively signed an informed consent form for modular surgery and total laryngectomy.

All procedures performed were in accordance with the ethical standards of the institutional Ethics Review Board and with the 1964 Helsinki declaration and its later amendments or comparable ethical standards.

\section{Surgery}

Indications to perform OPHL were: i) selected cases of early glottic cancer (cT2) not fit for transoral laser microsurgery (TLM), and ii) selected cases of locally intermediateadvanced disease (cT3-4a) with at least one disease-free CAU, no massive extralaryngeal spread (i.e. a limited diffusion to prelaryngeal tissues without invasion of the thyroid gland or of the infrahyoid muscles) and iii) acceptable general conditions and comorbidities.

General patient-related contraindications to OPHL included alcohol and drug abuse, or major comorbidities (heart failure, lung diseases, mellitus diabetes, or severe neurocognitive decay).

The open partial laryngectomies were performed and recorded according to the ELS classification ${ }^{6}$. According to the "modular" approach, the patients with glottic LSCC were initially approached with supracricoid resection; the procedure could intraoperatively change to supratracheal laryngectomy, according to macroscopic extension of the tumour and microscopic findings at frozen sections (positive or negative status of mucosal margins), with progressive widening of the resection, sparing at least one crico-arytenoid unit. All margins were also checked postoperatively on final histology and classified as positive/close/negative. A radical or modified radical neck dissection (RND and MRND, respectively) were performed in the event of clinically or radiologically proven lymph node involvement. Selective neck dissection (SND) of levels II-III-IV was performed electively for cT3-4a N0 disease, or with curative intent for clinically or radiologically limited node metastases. Bilateral neck dissection was routinely performed in cases of supraglottic spread. An ipsilateral paratracheal neck dissection was used in the event of disease extending to the hypoglottis. 
Postoperative radiotherapy (RT) was considered in locally advanced cases (pT3-T4a) with positive margins or multiple node metastases (pN2-3); chemo-radiotherapy (CRT) was scheduled in cases with extranodal extension, and angio-vascular or perineural invasion.

\section{Statistical analysis}

Fisher's exact test was used to calculate the association between different clinical and pathological parameters with OPHL modulation and disease recurrence rate. The logrank test and Kaplan-Meier survival function were used to calculate disease-free survival (DFS) for patients stratified by the selected variables.

A multivariate logistic model (Wald test) was applied to the same parameters (Fisher's exact test, $\mathrm{p}<0.10$ ) to identify independent prognostic factors in relation to recurrence rate and modulation surgery, and the relative $95 \%$ confidence intervals were calculated.

A p-value $<0.05$ was considered significant. The STATA 14 statistical package (Stata Corp., College Station, TX) was used for all analyses.

\section{Results}

Open partial horizontal laryngectomies

In this study a cohort of 72 LSCC patients (62 men and 10 women; mean age $61.1 \pm 8.6$ years, median 62 ) met the inclusion criteria.

An OPHL type II was performed in 49 cases, while a type III was carried out in 23 cases.

OPHL was modulated (from type II to type III) in 6 cases. Table I shows the distributions of preoperative clinical parameters in relation to the modulation of surgery. Hypoglottic tumour extension was the preoperative parameter that was significantly related with OPHL modulation.

Table I. Distributions of modulated OPHLs according to preoperative clinical (endoscopic/radiological) parameters.

\begin{tabular}{lcc} 
Parameter & Modulated OPHL & $\mathbf{p}^{*}$ \\
Posterior glottis & $5 / 36$ & 0.19 \\
Anterior glottis & $1 / 36$ & \\
Impaired/absent arytenoid motility & $5 / 44$ & 0.39 \\
Normal arytenoid motility & $1 / 28$ & \\
Radiological TCAS invasion & $5 / 47$ & 0.65 \\
No radiological TCAS invasion & $1 / 25$ & \\
Radiological CAU invasion & $5 / 30$ & 0.07 \\
No radiological CAU invasion & $1 / 42$ & \\
Hypoglottic extension & $6 / 32$ & 0.00 \\
No hypoglottic extension & $0 / 40$ & \\
\hline
\end{tabular}

"Fisher's exact test
The cases of LSCC were classified as follows: cT2 in 16; cT3 in 49; and cT4a in 8. Regional node status was classified as: $\mathrm{cN} 0$ in 56 cases; $\mathrm{cN} 1$ in 7 ; $\mathrm{cN} 2$ in 7 ; and $\mathrm{cN} 3$ in one. The pathological classification was: pT1 in 3 cases; pT2 in 6 ; pT3 in 44; and pT4a in 19. The pathological classification of cervical nodes was: pNX-0 in 56 cases; pN1 in 7; $\mathrm{pN} 2$ in 5 ; and $\mathrm{pN} 3$ in 4.

An ipsilateral neck dissection was performed in 63 cases, while a bilateral neck dissection in 4 cases with lesions crossing the midline. There was evidence of extranodal dissemination in 6 cases. Eleven patients received postoperative radiotherapy or CRT.

\section{Pathological findings}

At pathology, 10 patients had positive surgical margins, 45 negative and 17 closed. The positive margin was lateral (on the side of the spared arytenoid) in 6 cases, deep in 4, and caudal in 1 case. Vascular and perineural invasion were detected in 38 and 27 cases, respectively. As for pathological grade, this was well differentiated in 12 cases, moderately differentiated in 28 , poorly differentiated in 24 and indeterminate in 8 .

\section{Oncological outcomes}

Sixty-two patients had no relapse of disease, while 10 patients $(13 \%)$ experienced a disease recurrence after $15 \pm 6$ months. The mean follow-up was $34 \pm 6$ months (range 26-71 months). At latest follow-up, 61 patients (85\%) were alive and disease-free, 7 (9\%) were alive with disease, 2 $(3 \%)$ died of their disease and $2(3 \%)$ died with no evidence of disease. The final overall and disease-specific survival rates were $94 \%$ and $97 \%$, respectively.

Considering the 10 cases with positive margins, 3 patients underwent postoperative radiotherapy, chemo-radiotherapy was scheduled in 1 case with neck metastasis, while close follow-up was adopted in the remaining 6 cases. Two of the 10 patients experienced a local recurrence of disease and were submitted to total laryngectomy: one patient died of disease, the other was disease free at last follow-up. The OPHL was modulated in 1 patient, with caudal positive margin, who experienced no recurrence of disease.

Univariate and multivariate analysis of prognostic factors Results of the univariate analysis are shown in Table II. Patients with lymph node metastases had significantly higher recurrence rates and shorter DFS compared with pN0 patients. Statistical analysis found that patients who underwent OPHL type III and those with CAU involvement had significantly lower DFS compared with patients undergone OPHL type II and those without CAU involvement by the tumour. These patients had also higher recurrence rates, although no significant $\mathrm{p}$ values emerged from our analysis. 
Table II. Distribution of recurrence rate and disease-free survival (months) by main clinical and pathological parameters.

\begin{tabular}{|c|c|c|c|c|c|}
\hline & $\begin{array}{c}\text { No. of patients } \\
(\%)\end{array}$ & $\begin{array}{l}\text { Recurrence rate } \\
(\%)\end{array}$ & $p^{*}$ & $\begin{array}{c}\text { DFS } \\
\text { (Mean } \pm \text { SD) }\end{array}$ & $p^{* *}$ \\
\hline \multicolumn{6}{|l|}{ Age } \\
\hline Age $\geq 65$ & 24 & $4(16 \%)$ & 0.72 & $22 \pm 21$ & 0.83 \\
\hline Age $<65$ & 48 & $5(10 \%)$ & & $43 \pm 6$ & \\
\hline \multicolumn{6}{|l|}{ Pathological T classification } \\
\hline pT1 & 3 & $2(22 \%)$ & 0.60 & $24 \pm 31$ & 0.35 \\
\hline pT2 & 6 & & & & \\
\hline pT3 & 44 & $8(12 \%)$ & & $47 \pm 30$ & \\
\hline pT4a & 19 & & & & \\
\hline \multicolumn{6}{|l|}{ Pathological N classification } \\
\hline pNX-0 & 56 & $7(12 \%)$ & 0.05 & $49 \pm 4$ & 0.06 \\
\hline pN1 & 7 & $3(18 \%)$ & & $17 \pm 9$ & \\
\hline pN2 & 5 & & & & \\
\hline pN3 & 4 & & & & \\
\hline \multicolumn{6}{|l|}{ Resection margins } \\
\hline Negative & 62 & $10(16 \%)$ & 0.66 & $31 \pm 22$ & 0.95 \\
\hline Positive & 10 & $2(20 \%)$ & & $39 \pm 8$ & \\
\hline \multicolumn{6}{|l|}{ Vascular invasion } \\
\hline Negative & 34 & $4(11 \%)$ & 0.73 & $43 \pm 4$ & 0.86 \\
\hline Positive & 38 & $6(15 \%)$ & & $40 \pm 10$ & \\
\hline \multicolumn{6}{|l|}{ Perineural invasion } \\
\hline Negative & 45 & $7(15 \%)$ & 0.73 & $29 \pm 25$ & 0.44 \\
\hline Positive & 27 & $3(11 \%)$ & & $43 \pm 13$ & \\
\hline \multicolumn{6}{|l|}{ OPHL type } \\
\hline$\|$ & 49 & $4(8 \%)$ & 0.06 & $40 \pm 9$ & 0.05 \\
\hline III & 23 & $6(26 \%)$ & & $12 \pm 15$ & \\
\hline \multicolumn{6}{|l|}{ Anterior vs posterior } \\
\hline Posterior glottis & 36 & $8(22 \%)$ & 0.08 & $22 \pm 1$ & 0.04 \\
\hline Anterior glottis & 36 & $2(5 \%)$ & & $34 \pm 8$ & \\
\hline \multicolumn{6}{|l|}{ Arytenoid motility } \\
\hline Impaired/absent arytenoid motility & 45 & $9(20 \%)$ & 0.02 & $16 \pm 6$ & 0.07 \\
\hline Normal arytenoid motility & 27 & $0(0 \%)$ & & $18 \pm 8$ & \\
\hline \multicolumn{6}{|l|}{ TCAS involvement } \\
\hline Radiological TCAS invasion & 47 & $8(17 \%)$ & 0.47 & $17 \pm 8$ & 0.43 \\
\hline No radiological TCAS invasion & 25 & $2(8 \%)$ & & $27 \pm 1$ & \\
\hline \multicolumn{6}{|l|}{ CAU involvement } \\
\hline Radiological CAU invasion & 30 & $7(23 \%)$ & 0.08 & $31 \pm 11$ & 0.04 \\
\hline No radiological CAU invasion & 42 & $3(7 \%)$ & & $25 \pm 4$ & \\
\hline \multicolumn{6}{|l|}{ Hypoglottic extension } \\
\hline Endoscopic hypoglottic extension & 32 & $7(21 \%)$ & 0.09 & $20 \pm 4$ & 0.10 \\
\hline No endoscopic hypoglottic extension & 40 & $3(7 \%)$ & & $26 \pm 4$ & \\
\hline
\end{tabular}

"Fisher's exact test; " Log-rank test

Patients with normal arytenoid motility experienced significantly lower recurrence rates compared with patients with impaired/absent motility. Patients with locally inter- mediate-advanced stage disease (pT3-4), positive margins, posterior glottic tumours and radiological involvement of thyro-crico-arytenoid space (TCAS) and hypoglottic region 
had a higher recurrence rate and shorter DFS, although the differences were not significant.

Multivariate analysis confirmed that hypoglottic extension of the tumour was the only independent predictive factor for surgical modulation (Wald test, $\mathrm{p}=0.05$; odds ratio 2.1; 95\% confidence interval 1.25-4.35). The pathological finding of neck metastasis was an independent negative prognostic factor in terms of recurrence rate (Tab. III).

\section{Discussion}

Modular surgery is a patient- and tumour-tailored surgical approach that is gaining increasing importance in modern surgery. Considering laryngeal cancer, OPHL is the modular procedure par excellence. As previously reported, when approaching an OPHL, the surgeon should refer to a surgical plan rather than to a single procedure ${ }^{8}$.

Modular surgical approaches to organ resection, related to the tumour site and extension, have already been proposed for other cancers, including gastric, liver and pancreatic cancers ${ }^{9-13}$. In dermatological surgery, Mohs micrographic surgery (MMS) has become the gold standard for treatment of cutaneous malignancies. It consists with removal of the neoplasm, in a step-by-step fashion, with progressive tissue exeresis checked with frozen sections, up to complete removal of the lesion. Histopathologic examination is key to the high cure rates achieved with MMS ${ }^{14}$.
It is worth noting that every type of conservative surgery, including OPHL, necessarily needs a very accurate preoperative diagnostic work-up in order to analyze the real extension of the tumour, as well as intraoperative confirmation of surgical margins with frozen sections. In the case of modular surgery, the role of histological examination is even more relevant since it determines modulation towards the more radical procedure.

In the present study, a relatively high number of positive margins was reported $(13.9 \%)$. This could be related to: i) the discrepancy between intraoperative and definitive results of the pathological examination, ii) the final positivity of deep margins, since we intraoperatively sent only superficial mucosal margins, and iii) to the high number of locally advanced tumours (pT3-T4a: 63 cases, 87\%).

The possibility to modulate the level of the caudal resection represents a peculiarity and one of the main advantages of partial horizontal laryngectomies. The diffusion and the standardisation of OPHL are due to ELS, and in particular to the efforts of Succo and coworkers ${ }^{6}$.

This surgical modular approach was demonstrated to be a valid and effective therapeutic choice for selected patients with glottic or transglottic laryngeal cancer with subglottic extension, not only in terms of oncologic results, but also in terms of functional outcomes ${ }^{15,16}$.

However, OPHL type II had been demonstrated to warrant overall better functional results and lower complication

Table III. Multivariate analysis of main clinical and pathological parameters.

\begin{tabular}{|c|c|c|c|c|}
\hline & Odds ratio & $p^{*}$ & $95 \%$ confidence interval & $p^{* *}$ \\
\hline \multicolumn{5}{|l|}{ Pathological N classification } \\
\hline $\mathrm{pN}+$ & 2.35 & 0.05 & $\begin{array}{c}\text { Reference group } \\
1.55-7.85\end{array}$ & 0.05 \\
\hline \multicolumn{5}{|l|}{ OPHL type } \\
\hline III & 1.80 & 0.06 & $\begin{array}{c}\text { Reference group } \\
0.85-2.35\end{array}$ & 0.07 \\
\hline Posterior glottis & 1.50 & 0.08 & $\begin{array}{c}\text { Reference group } \\
1.15-5.55\end{array}$ & 0.08 \\
\hline \multicolumn{5}{|l|}{ Arytenoid motility } \\
\hline Impaired/absent arytenoid motility & 3.20 & 0.02 & $\begin{array}{c}\text { Reference group } \\
1.35-15.5\end{array}$ & 0.07 \\
\hline \multicolumn{5}{|l|}{ Hypoglottic extension } \\
\hline Endoscopic hypoglottic extension & 1.55 & 0.09 & $\begin{array}{c}\text { Reference group } \\
0.65-8.55\end{array}$ & 0.25 \\
\hline
\end{tabular}

Fisher's exact test; " Wald test 
rates. In 2017, Lucioni et al. reported that postoperative laryngeal obstruction of the neoglottis after OPHL occurred in 49 of 446 patients who had OPHL type II (11\%) and in 36 of 105 patients who had OPHL type III (34\%). Such a complication in most cases can be managed with transoral laser microsurgery (TLM) to resolve the neolaryngeal stenosis. Also, the number of procedures necessary to treat the stenosis differed between the procedures. Actually, the authors reported that $1.6 \pm 1.2$ TLM procedures were necessary to manage the stenosis after OPHL type II, while $2.2 \pm 1.8$ were necessary after OPHL type III. The final decannulation rate after OPHL type II was $92 \%$ vs $86 \%$ after OPHL type III ${ }^{17}$.

In 2015, Schindler and coworkers published an exhaustive comparison of functional outcomes of OPHL type IIa and IIIa, in terms of swallowing, voice and quality of life. Their results, showing the effectiveness of OPHL type IIIa, denoted a trend toward better functional outcomes of OPHL IIa, although significant differences were found in swallowing only for residue with solids and for voice intelligibility ${ }^{18}$.

All patients must be preoperatively informed about the eventuality of shifting from supracricoid to supratracheal laryngectomy. Specific consent including all possible extensions of the procedure, to be signed by the patient, is thus needed ${ }^{8}$. At our Institution, patients are routinely informed about the possibility of intraoperative modulation of partial laryngectomy and that, in extreme cases, the pro- cedure can even be converted to total laryngectomy. In most cases, however, correct preoperative staging can predict the possibility of conservative surgery, rather than the need for radical laryngectomy. For the same reasons, OPHL type I is not usually part of the modularity issue, since correct endoscopic and radiological diagnostic work-up can exclude the involvement of the glottis by a supraglottic cancer.

To our knowledge, on the other hand, there are no clear predictive parameters of the modulation of OPHL. In the present study, we investigated the relevance of clinical (endoscopic and radiological) parameters to predict the modulation of the OPHL.

Univariate and multivariate analysis found that hypoglottic extension of the tumour was the most significant preoperative parameter to predict the possibility of intraoperatively modulating the OPHL.

In cases with endoscopic and radiological suspicion of the hypoglottic region, OPHL lets the surgeon start with a supracricoid approach, with the possibility to lower the resection, modulating the procedure to a supratracheal laryngectomy, according to the results of intraoperative frozen sections.

Clearly, the possibility to modulate the OPHL must not reduce the importance of a scrupulous preoperative staging. In the present study, all patient underwent preoperative flexible endoscopy in an outpatient setting, contrastenhanced neck MRI, if available, or CT scan and direct laryngoscopy under general anaesthesia using rigid $0^{\circ}, 30^{\circ}$
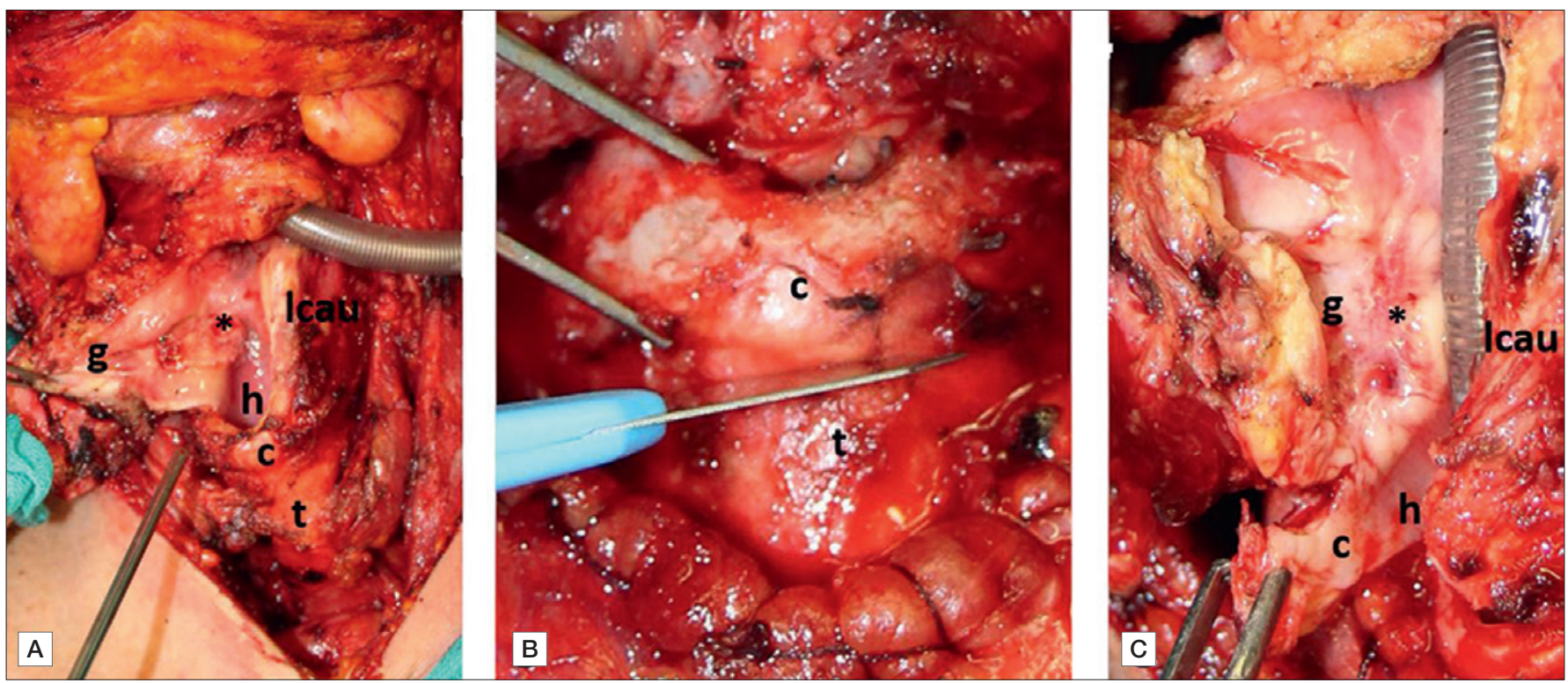

Figure 1. A. Opening the larynx during supracricoid approach to assess the tumour extension. B. After frozen sections results, the caudal incision is lowered under the cricoid cartilage (supratracheal resection). C. Removal of the cricoid ring en bloc with the specimen. Captions. c: cricoid ring; g: glottis; h: hypoglottis; Icau: left crico-arytenoid unit; t: trachea; ": tumour. 
and $70^{\circ}$ telescopes in white light and narrow band imaging to assess the mucosal margins of the neoplasm ${ }^{19}$.

On the other hand, the hypoglottic extension did not significantly impact oncological outcomes (Tab. II). This is probably due to the good tumour control by OPHL type III in cases with initial hypoglottic extension of the tumour. Moreover, the only patient with caudal positive margins who had modulation of the OPHL did not experience local recurrence of the disease.

The recent literature is focusing on the negative prognostic relevance of posterior spreading of the glottic tumour ${ }^{20-25}$. This finding was confirmed by our results (Tab. II), although only the posterior glottic localisation and the impaired/absent arytenoid mobility were related to significantly lower DFS $(p=0.04)$ and higher recurrence rate $(p=0.02)$, respectively. Interestingly, our results ruled out glottic localisation (anterior vs posterior), arytenoid mobility and the radiological finding of TCAS or CAU involvement as predictors of OPHL modulation. This could be related to the preoperative selection of cases. Actually, patients with endoscopic evidence of posterior glottic lesions or impaired/ absent arytenoid mobility were directly approached with OPHL type III because of the high risk of crico-arytenoid joint involvement by the tumour. Similarly, in case of radiological suspicion of TCAS or CAU invasion, these structures were directly sacrificed (OPHL type III).

In the present study, multivariate analysis (Tab. III) confirmed that only a pathological finding of neck metastasis was an independent negative prognostic factor in terms of recurrence rate $(p=0.05)$, consistent with the current literature on laryngeal cancer ${ }^{26}$. On the other hand, the impaired arytenoid motility, CAU invasion and need for OPHL type III were not independent negative prognostic factors. Once again, this is reasonably due to the fact that all these situations are possible in case of posterior glottic localisation of the tumour.

\section{Conclusions}

OPHL represents the modular surgery par excellence to approach the glottic LSCC. The endoscopic and radiological finding of hypoglottic extension is the preoperative parameter that is most informative in predicting intraoperative OPHL modulation. Patients affected by tumours with hypoglottic extension and eligible for OPHL type II should be preoperatively informed about the possibility of an intraoperative switch towards OPHL type III. Patients with posterior glottic lesions or impaired/absent arytenoid mobility should be directly approached with OPHL type III or total laryngectomy.

\section{Acknowledgements}

The authors thank all the medical and paramedical staff at the Otolaryngology Unit - Vittorio Veneto Hospital, for collecting the follow-up data, and the Association "Amici della voce" (Friends of the Voice) for support in preparing the manuscript.

\section{References}

1 Alonso JM. Functional surgery in cancer of the larynx; subtotal horizontal laryngectomy. Ann Otolaryngol 1957;74:75-80.

2 Piquet JJ, Desaulty A, Decroix G. La crico-hyoido-épiglottopexie. Tecnique opératoire et résultats fonctionnels. Ann Otolaryngol Chir Cervicofac 1974;91:681-90.

3 Labayle J, Bismuth R. Total laryngectomy with reconstitution. Ann Otolaryngol Chir Cervicofac 1971;88:219-28.

4 Serafini I. Reconstructive laryngectomy. Rev Laryngol Otol Rhinol (Bord) 1972;93:23-38.

5 Rizzotto G, Succo G, Lucioni M, et al. Subtotal laryngectomy with tracheohyoidopexy: a possible alternative to total laryngectomy. Laryngoscope. 2006;116:1907-17. https://doi.org/10.1097/01. mlg.0000236085.85790.d5

6 Succo G, Peretti G, Piazza C, et al. Open partial horizontal laryngectomies: a proposal for classification by the working committee on nomenclature of the European Laryngological Society. Eur Arch Otorhinolaryngol 2014;271:2489-96. https://doi.org/10.1007/s00405014-3024-4

7 Brierley JD, Gospodarowicz MK, Wittekind C. TNM Classification of Malignant Tumours. $8^{\text {th }}$ ed. Chichester, UK: John Wiley and Sons; 2017.

8 Giordano L, Di Santo D, Crosetti E, et al. Open partial horizontal laryngectomies: is it time to adopt a modular form of consent for the intervention? Acta Otorhinolaryngol Ital 2016;36:403-7. https://doi. org/10.14639/0392-100X-769

9 Chang YR, Han SS, Park SJ, et al. Surgical outcome of pancreatic cancer using radical antegrade modular pancreatosplenectomy procedure. World J Gastroenterol 2012;18:5595-600. https://doi. org/10.3748/wjg.v18.i39.5595

10 Brar S, Law C, McLeod R, et al. Defining surgical quality in gastric cancer: a RAND/UCLA appropriateness study. J Am Coll Surg 2013;217:347-57.e1. https://doi.org/10.1016/j.jamcollsurg.2013.01.067

11 Masiak-Segit W, Rawicz-Pruszyński K, Skórzewska M, et al. Surgical treatment of pancreatic cancer. Pol Przegl Chir 2018;90:45-53. https://doi.org/10.5604/01.3001.0011.7493

12 Li M, Wang XA, Wang L, et al. A three-step method for modular lymphadenectomy in gastric cancer surgery: the ability to retrieve sufficient lymph nodes and improve survival. Am J Surg 2018;215:91-6. https://doi.org/10.1016/j.amjsurg.2017.01.042

13 Wu X, Rao J, Zhou X, et al. Partial ALPPS versus complete ALPPS for staged hepatectomy. BMC Gastroenterol 2019;19:170. https://doi. org/10.1186/s12876-019-1090-1

14 Tolkachjov SN, Brodland DG, Coldiron BM, et al. Understanding Mohs micrographic surgery: a review and practical guide for the nondermatologist. Mayo Clin Proc 2017;92:1261-71. https://doi. org/10.1016/j.mayocp.2017.04.009

15 Succo G, Crosetti E, Bertolin A, et al. Benefits and drawbacks of open partial horizontal laryngectomies, Part B: Intermediate and selected advanced stage laryngeal carcinoma. Head Neck 2016;38(Suppl 1):E649-57. https://doi.org/10.1002/hed.24064. 
16 Succo G, Fantini M, Rizzotto G. Supratracheal partial laryngectomy: indications, oncologic and functional results. Curr Opin Otolaryngol Head Neck Surg 2017;25:127-32. https://doi.org/10.1097/ MOO.0000000000000344

17 Lucioni M, Bertolin A, Lionello M, et al. Transoral laser microsurgery for managing laryngeal stenosis after reconstructive partial laryngectomies. Laryngoscope 2017;127:359-65. https://doi.org/10.1002/lary.26056

18 Schindler A, Pizzorni N, Fantini M, et al. Long-term functional results after open partial horizontal laryngectomy type IIa and type IIIa: A comparison study. Head Neck 2016;38(Suppl 1):E1427-35. https:// doi.org/10.1002/hed.24254

19 Crosetti E, Pilolli F, Succo G. A new strategy for endoscopic staging of laryngeal carcinoma: multistep endoscopy. Acta Otorhinolaryngol Ital 2012;32:175-81.

20 Succo G, Crosetti E, Bertolin A, et al. Treatment for T3 to T4a laryngeal cancer by open partial horizontal laryngectomies: prognostic impact of different pathologic tumor subcategories. Head Neck 2018;40:1897-908. https://doi.org/10.1002/hed.25176

21 Lucioni M, Lionello M, Machin P, et al. Sclerosis of the arytenoid cartilage and glottic carcinoma: A clinical-pathological study. Head Neck 2019;41:72-8. https://doi.org/10.1002/hed.25372
22 Succo G, Cirillo S, Bertotto I, et al. Arytenoid fixation in laryngeal cancer: radiological pictures and clinical correlations with respect to conservative treatments. Cancers (Basel) 2019;11:360. https://doi. org/10.3390/cancers 11030360

23 Del Bon F, Piazza C, Lancini D, et al. Open partial horizontal laryngectomies for T3-T4 laryngeal cancer: prognostic impact of anterior vs. posterior laryngeal compartmentalization. Cancers (Basel) 2019;11:289. https://doi.org/10.3390/cancers11030289

24 Crosetti E, Bertolin A, Molteni G, et al. Patterns of recurrence after open partial horizontal laryngectomy types II and III: univariate and logistic regression analysis of risk factors. Acta Otorhinolaryngol Ital 2019;39:235-43. https://doi.org/10.14639/0392-100X-2409

25 Lucioni M, Lionello M, Guida F, et al. The thyro-cricoarytenoid space (TCAS): clinical and prognostic implications in laryngeal cancer. Acta Otorhinolaryngol Ital 2020;40:106-12. https://doi. org/10.14639/0392-100X-N0373

26 Bradford CR, Ferlito A, Devaney KO, et al. Prognostic factors in laryngeal squamous cell carcinoma. Laryngoscope Investig Otolaryngol 2020;5:74-81. https://doi.org/10.1002/lio2.353 